\title{
What can we do to reduce the viral reservoir in HIV-1-infected individuals?
}

\author{
“...early treatment of HIV-1 is an effective way to impact (but not \\ prevent) the establishment of the HIV-1 reservoir.”
}

\section{Christopher W Pohlmeyer1, Victoria E Walker-Sperling' \& Joel N Blankson* ${ }^{*, 1}$}

First draft submitted: 16 April 2016; Accepted for publication: 19 April 2016;

Published online: 15 July 2016

\begin{abstract}
Combination antiretroviral therapy (cART) inhibits HIV-1 replication, preventing CD4 depletion and the development of opportunistic infections. However, it does not lead to a cure of HIV-1 infection mainly due to viral reservoirs that persist despite treatment. Latently infected resting memory $\mathrm{CD}^{+} \mathrm{T}$ cells with integrated proviral DNA are the best-described reservoir of HIV-1 [1]. Macrophages and other myeloid cells are also targets of infection and may represent cellular reservoirs of infection [1]. In addition to these cellular reservoirs, there may be anatomical reservoirs or sanctuaries, such as the central nervous system. It is possible that in these sites, poor penetration of antiretroviral drugs may lead to ongoing viral replication. In order to achieve a sterilizing cure, all reservoirs of HIV-1 will have to be eliminated.
\end{abstract}

\section{Limiting the establishment of} reservoirs: early treatment with CART

The latent reservoir is established very early in primary infection [2]. Very high levels of viremia are achieved during this phase of infection, and the magnitude of viremia correlates with the frequency of infected resting $\mathrm{CD}^{+} \mathrm{T}$ cells [3]. Multiple studies have shown that while early treatment with cART does not prevent the establishment of latency, it does significantly reduce the size of the viral reservoir possibly as a result of the blunted viremia. In recent studies where patients were treated during the very earliest stages of HIV-1 infection, the frequency of infected $\mathrm{CD}^{+} \mathrm{T}$ cells was found to be extremely low and in some cases below the limit of detection $[4,5]$. Furthermore, there have been several cases of post-treatment control, where patients who were treated during early infection maintained control of viral replication after the cessation of treatment [6] potentially as a result of the small size of the reservoir and the fact that reactivation of latently infected $\mathrm{CD}^{+} \mathrm{T}$ cells is a stochastic process.

\section{Reducing the size of the established reservoir: chemotherapy \& transplantation}

While early treatment with cART is clearly an effective way to limit the size of viral reservoirs, it requires that primary infection be recognized and treated, something that is challenging to accomplish on a large scale. It also has no effect on the large number of already chronically infected patients. There have been two broad strategies that have been applied to reduce the size of the pre-existing reservoir. The first involves

\section{KEYWORDS}

- AIDS • eradication • HIV

- immunity 
"It has also been shown that the reversal of latency in vitro does not lead to death of the infected cell.” using chemotherapy to eliminate host lymphocytes in patients with malignancies followed by bone marrow or stem cell transplantation. A recent study found that in two patients with malignancies who were treated with chemotherapy and allogeneic hematopoietic stem cell transplantations (HSCT), there was almost complete chimerism and the frequency of latently infected $\mathrm{CD}^{+} \mathrm{T}$ cells was less than 1 in 150 million in both patients [7], much lower than the median of approximately 1 in 1 million in patients on suppressive cART regimens. However, the patients were not cured as cessation of treatment led to rebound viremia [7]. Thus, while the strategy of chemotherapy followed by transplantation can lead to marked reduction in the number of latently infected $\mathrm{CD}^{+} \mathrm{T}$ cells, it will not routinely lead to a cure of HIV-1 infection due to the persistence of a small reservoir of infected cells. However, a variation of this strategy led to the only known cure of HIV-1 infection: the Berlin patient [8]. In this case, the transplanted cells were from a donor who had a mutation in the gene for CCR5. Since this mutation affects the expression of an HIV-1 co-receptor, any residual virus that was present post-transplantation in the Berlin patient would not be able to infect the donor cells and, therefore, could not re-establish infection. If this strategy of transplantation with CCR5-deficient cells can be replicated, it is possible that other HIV-1-infected patients with malignancies can be cured.

\section{Reducing the size of the established reservoir: latency reversal agents}

Chemotherapy and transplantation is not a practical method at this time for reservoir reduction in patients who do not have malignancies, and therefore other strategies are needed. This had led to the search for small molecules that can reverse latency without causing potentially toxic global T-cell activation. There have been several classes of small molecules, including histone deactylase inhibitors and protein kinase $\mathrm{C}$ agonists, which have successfully induced viral transcription from latently infected $\mathrm{CD} 4^{+} \mathrm{T}$ cells in vitro, and combinations of some of these drugs leads to a synergistic effect [9]. The combination of bryostatin and romidepsin, for example, reverses latency to a degree that approaches the levels seen when $\mathrm{CD} 4^{+} \mathrm{T}$ cells are fully activated with PMA and ionomycin [9]. The clinical experience with these latency reversal agents has been mixed; HDAC inhibitors such as vorinostat, panabinostat and romidepsin and the aldehyde dehydrogenase inhibitor disulfiram have caused blips of viremia but no detectable decrease in the size of the viral reservoir in patients [10]. There are potentially several different explanations for this. One is that the size of the latent reservoir would not be noticeably impacted by the reactivation of the few cells that it would take to cause a low level blip in viremia. Indeed, if the burst size of an infected cell is 10,000 copies of HIV-1 RNA, then as few as 50 reactivated CD $4^{+}$ $T$ cells could theoretically lead to a viral load of 100 copies $/ \mathrm{ml}$ in a patient. This is a very small number given the estimate of 1 million latently infected cells in a patient [11]. A recent study suggested that the true size of the reservoir could in fact be 60-times larger [12].

\section{Reducing the size of the established reservoir: shocking \& killing}

It has also been shown that the reversal of latency in vitro does not lead to death of the infected cell [13]. If this holds true in vivo it would suggest that treatment with latency reversal agents (LRAs) would only lead to a reduction in the size of the reservoir if it were combined with treatments that would kill the reactivated cell. This shock and kill approach has renewed interest in harnessing the immune system to kill HIVinfected cells. HIV-1-infected elite suppressors (ES) may be a model for immune-mediated killing of reactivated cells. These are patients who maintain viral loads below the limit of detection without cART. Some of these patients appear to be infected with fully replication-competent virus [14], and their frequency of latently infected $\mathrm{CD}^{+} \mathrm{T}$ cells is low and does not increase over time in spite of ongoing viral replication and viral evolution. These patients have potent HIV-specific CD8 ${ }^{+}$T-cell responses [15] and it is likely that these responses can kill latently infected cells as they reactivate, thereby preventing breakthrough viremia. Furthermore, in monkey models of HIV infection, $\mathrm{CD}^{+}{ }^{+} \mathrm{T}$ cells induced by a cytomegalovirus-based vaccine are capable of completely eradicating the simian immunodeficiency virus reservoir [16]. While the $\mathrm{CD}^{+} \mathrm{T}$ cells in these monkeys are atypical in that they are restricted by class II major histocompatability complex molecules, the study does suggest that immunotherapy can eliminate viral reservoirs.

Several studies have in fact suggested that $\mathrm{CD}^{+} \mathrm{T}$ cells can kill HIV-1-infected cells as they 
are reactivated in vivo $[13,17]$, but another study showed that primary $\mathrm{CD} 8{ }^{+} \mathrm{T}$ cells from chronically infected patients on cART are ineffective at eliminating reactivated $\mathrm{CD}^{+} \mathrm{T}$ cells [18]. It has recently been shown that HDAC inhibitors adversely impact the effect of HIV-specific clones [19] and in another study, the PKC agonist bryostatin was also shown to impair primary CD8 ${ }^{+} \mathrm{T}$-cell responses [20]. The combination of bryostatin and the HDAC inhibitor romidepsin, which was shown to be effective at reversing latency in vitro, significantly reduces the ability of HIV-specific CD8 ${ }^{+} \mathrm{T}$ cells from ES to suppress HIV-1 replication [20]. Fortunately, not all combinations of LRAs had this effect on HIVspecific CD8 ${ }^{+} \mathrm{T}$-cell responses and it might be possible to select agents that would potentially not be immunosuppressive.

Other potential strategies could include treatment with HIV-specific antibodies that induce antibody-dependent cell-mediated cytotoxicity or HIV-specific antibodies conjugated to toxins. One such molecule given in conjunction with cART was more effective at reducing the size of the viral reservoir in infected humanized mice than cART alone [21]. There have also been bispecific antibodies developed that recognize both HIV-1 envelope (leading to targeting of infected cells) and CD3 leading to the activation of effector $\mathrm{CD} 4^{+}$and $\mathrm{CD} 8^{+}$
T cells. These molecules have been effective at targeting latently infected cells in vitro and may have great potential in cure strategies.

\section{Conclusion}

In summary, early treatment of HIV-1 is an effective way to impact (but not prevent) the establishment of the HIV-1 reservoir. Chemotherapy with transplantation can lead to a marked reduction in the size of the established reservoir and transplantation of cells that are resistant to HIV-1 infection has led to a cure of infection. Latency reversal agents used in conjunction with immunotherapy may eventually also be effective, but more studies are needed to determine how much of an impact this approach will have on the size of viral reservoirs. More work is also needed to determine how these strategies impact myeloid cells and anatomical reservoirs such as the central nervous system.

\section{Financial \& competing interests disclosure}

The authors are funded by the NIH. The authors have no other relevant affiliations or financial involvement with any organization or entity with a financial interest in or financial conflict with the subject matter or materials discussed in the manuscript apart from those disclosed.

No writing assistance was utilized in the production of this manuscript.

\section{References}

1 Eisele E, Siliciano RF. Redefining the viral reservoirs that prevent HIV-1 eradication. Immunity 37(3), 377-388 (2012).

2 Chun TW, Engel D, Berrey MM, Shea T, Corey L, Fauci AS. Early establishment of a pool of latently infected, resting CD4(+) T cells during primary HIV-1 infection. Proc. Natl Acad. Sci. USA 95(15), 8869-8873 (1998).

3 Blankson JN, Finzi D, Pierson TC et al. Biphasic decay of latently infected $\mathrm{CD} 4^{+} \mathrm{T}$ cells in acute human immunodeficiency virus type 1 infection. J. Infect. Dis. 182(6), 1636-1642 (2000).

4 Ananworanich J, Sacdalan CP, Pinyakorn S et al. Virological and immunological characteristics of HIV-infected individuals at the earliest stage of infection. J. Virus Erad. 2, 43-48 (2016).

5 Hatano H, Bacon O, Cohen S et al. Lack of detectable HIV DNA in a PrEP study participant treated during hyperacute HIV infection. Presented at: The Conference of Retroviruses and Opportunistic Infections. MA, USA, 3-6 March 2014.

6 Persaud D, Gay H, Ziemniak C et al. Absence of detectable HIV-1 viremia after treatment cessation in an infant. N. Engl. J. Med. 369(19), 1828-1835 (2013).

7 Henrich TJ, Hanhauser E, Marty FM et al. Antiretroviral-free HIV-1 remission and viral rebound after allogeneic stem cell transplantation: report of 2 cases. Ann. Intern. Med. 161(5), 319-327 (2014).

8 Hütter G, Nowak D, Mossner M et al. Long-term control of HIV by CCR5 Delta32/ Delta32 stem-cell transplantation. N. Engl. J. Med. 360 (7), 692-698 (2009).

9 Laird GM, Bullen CK, Rosenbloom DI et al. Ex vivo analysis identifies effective HIV-1 latency-reversing drug combinations. J. Clin. Invest. 125(5), 1901-1912 (2015).

10 Spivak AM, Planelles V. HIV-1 eradication: early trials (and tribulations). Trends Mol. Med. 22(1), 10-27 (2016).
11 Chun TW, Carruth L, Finzi D et al. Quantification of latent tissue reservoirs and total body viral load in HIV-1 infection. Nature 387(6629), 183-188 (1997).

12 Ho YC, Shan L, Hosmane NN et al. Replication-competent noninduced proviruses in the latent reservoir increase barrier to HIV-1 cure. Cell 155(3), 540-551 (2013).

13 Shan L, Deng K, Shroff NS et al. Stimulation of HIV-1-specific cytolytic T lymphocytes facilitates elimination of latent viral reservoir after virus reactivation. Immunity 36(3), 491-501 (2012).

14 Blankson JN, Bailey JR, Thayil S et al. Isolation and characterization of replicationcompetent human immunodeficiency virus type 1 from a subset of elite suppressors. J. Virol. 81(5), 2508-2518 (2007).

15 Migueles SA, Connors M. Success and failure of the cellular immune response against HIV-1. Nat. Immunol. 16(6), 563-570 (2015).

16 Hansen SG, Piatak M Jr, Ventura AB et al. Immune clearance of highly pathogenic SIV 
EDITORIAL Pohlmeyer, Walker-Sperling \& Blankson

infection. Nature 502(7469), 100-104 (2013).

17 Sung JA, Lam S, Garrido C et al. Expanded cytotoxic T-cell lymphocytes target the latent HIV reservoir. J. Infect. Dis. 212(2), 258-263 (2015).

18 Walker-Sperling VE, Cohen VJ, Tarwater PM, Blankson JN. Reactivation kinetics of HIV-1 and susceptibility of reactivated latently infected $\mathrm{CD}^{+}{ }^{+} \mathrm{T}$ cells to HIV-1-specific CD8 ${ }^{+}$T cells. J. Virol. 89(18), 9631-9638 (2015).
19 Jones RB, O'Connor R, Mueller S et al. Histone deacetylase inhibitors impair the elimination of HIV-infected cells by cytotoxic T-lymphocytes. PLoS Pathog. 10(8), e1004287 (2014).

20 Walker-Sperling VE, Pohlmeyer CW, Tarwater PM, Blankson JN. The effect of latency reversal agents on primary $\mathrm{CD} 8^{+} \mathrm{T}$ cells: implications for shock and kill strategies for Human Immunodeficiency Virus eradication. Presented at: The Conference of Retroviruses and Opportunistic Infections. MA, USA, 22-25 February 2016.
21 Denton PW, Long JM, Wietgrefe SW et al. Targeted cytotoxic therapy kills persisting HIV infected cells during ART. PLoS Pathog. 10(1), e1003872 (2014).

22 Sung JA, Pickeral J, Liu L et al. Dual-affinity re-targeting proteins direct $\mathrm{T}$ cell-mediated cytolysis of latently HIV-infected cells. J. Clin. Invest. 125(11), 4077-4090 (2015). 